\title{
Tribute to Hirji Sorab Adenwalla-A Unique Medical Missionary
}

\author{
P. V. Narayanan ${ }^{1}$ \\ ${ }^{1}$ Consultant Plastic Surgeon, JMMC\&RI, Kerala, India
}

Indian J Plast Surg:2020;53:171-176

"Take up one idea. Make that one idea your life; dream of it; think of it; live on that idea. Let the brain, the body, muscles, nerves, every part of your body be full of that idea, and just leave every other idea alone. This is the way to success, and this is the way great spiritual giants are produced."

\section{- Swami Vivekananda ${ }^{1}$}

The above quote epitomizes what Hirji Sorab Adenwalla (-Fig. 1) followed; the "idea" in his case being a medical missionary worker in general, and caring for children with cleft lip and palate in particular. It is little wonder that he rose to be a giant in his field.

Hirji Sorab Adenwalla was born on June 5, 1930. He completed his graduation and postgraduation in Surgery at the Seth Ghordandas Sunderdas Medical College and KEM Hospital, Bombay, 1955. He then worked as a Senior Registrar at the Bai Jerbai Wadia Hospital for Children, Bombay, where he gained his experience in Pediatric and Plastic surgery and came under the influence of Charles Pinto, whose work on cleft lip and palate children inspired him to take up cleft surgery. Whenever he spoke of Charles Pinto, ${ }^{2}$ it was with awe

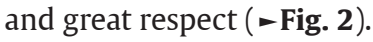

He was desirous of joining Albert Schweitzer in Africa as a medical missionary. However, bowing to family pressure, he agreed not to go there, but got them to agree to accept his posting at the Jubilee Mission Hospital in Thrissur in 1959. Through sheer hard work and versatile talent in surgery and allied fields, he developed this dispensary into a full-fledged hospital for the wholesome treatment of the poor masses of Thrissur specifically and Kerala as a whole.

In his initial years, he was an all-rounder, and treated all ailments that he was presented with. Thus, he was a general physician, general surgeon, pediatrician, pediatric surgeon, obstetrician, neurosurgeon, thoracic surgeon, surgical gastroenterologist, and urologist rolled into one. He was also his own anesthetist, radiology technician, and even the
Address for correspondence P.V. Narayanan, MS, FRCS, Consultant Plastic Surgeon, JMMC\&RI, Kerala, 680005, India (e-mail: Charlespinto102@gmail.com).

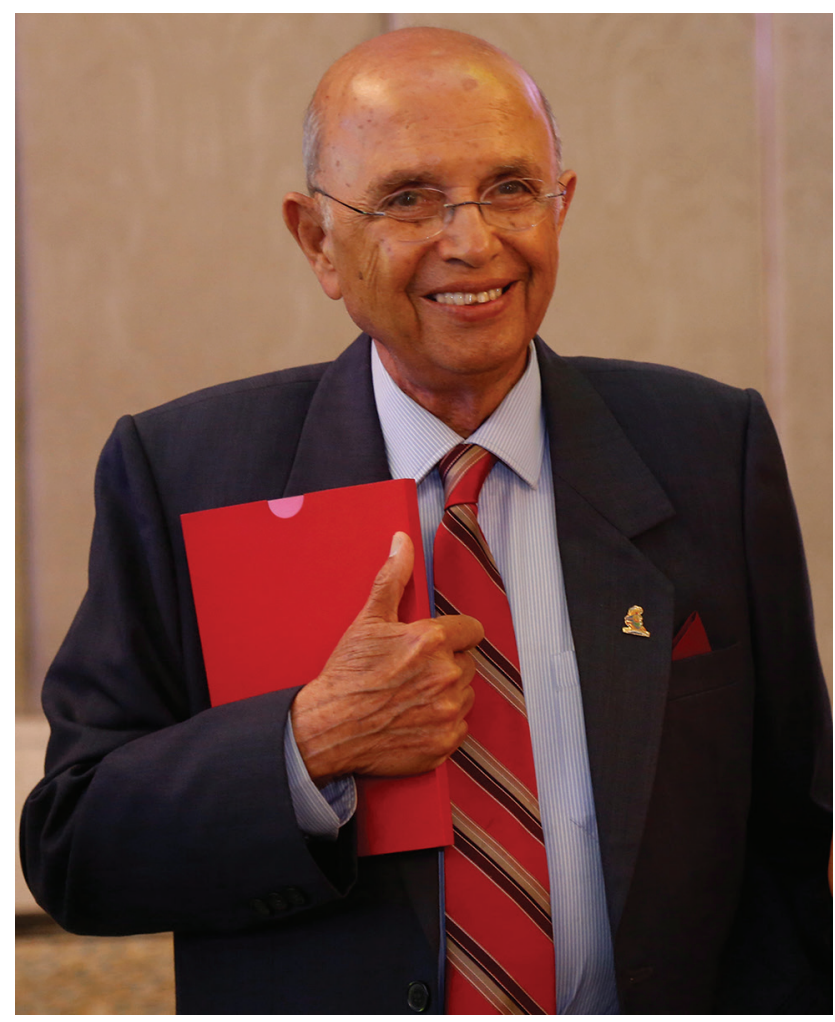

Fig. 1 Dr. H.S. Adenwalla.

gatekeeper of the hospital, having to open the gates to let in emergency patients at night.

In the initial years at Thrissur, he was the sole surgeon in the hospital and deftly handled a variety of surgeries, including all types of gastrointestinal surgeries, thoracotomies, pediatric surgery, gynecological surgery, orthopedic surgery, ventriculoperitoneal shunt for hydrocephalus, and even closed mitral commissurotomy ( $\boldsymbol{\text { Fig. }}$ 3)! Few would probably know that his first publication ${ }^{3}$ (that is even now being cited) was not on cleft surgery or even plastic surgery but on clavicular fractures. He devised a technique of excision of the
DOI https://doi.org/

$10.1055 / \mathrm{s}-0040-1715534$

ISSN 0970-0358.
(C)2020 Association of Plastic Surgeons of India
License terms

(1) (1) $\ominus \circledast$ 


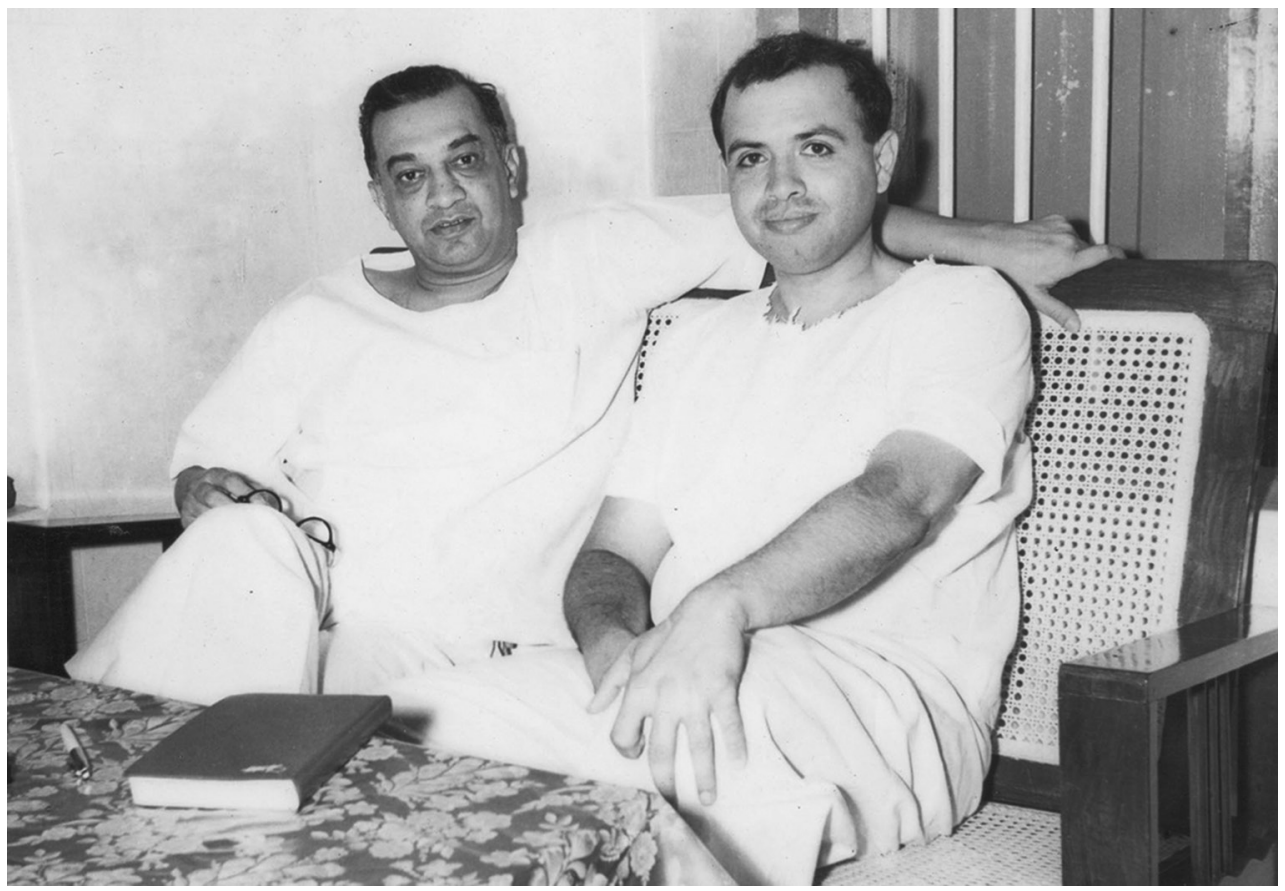

Fig. 2 With his mentor Charles Pinto.

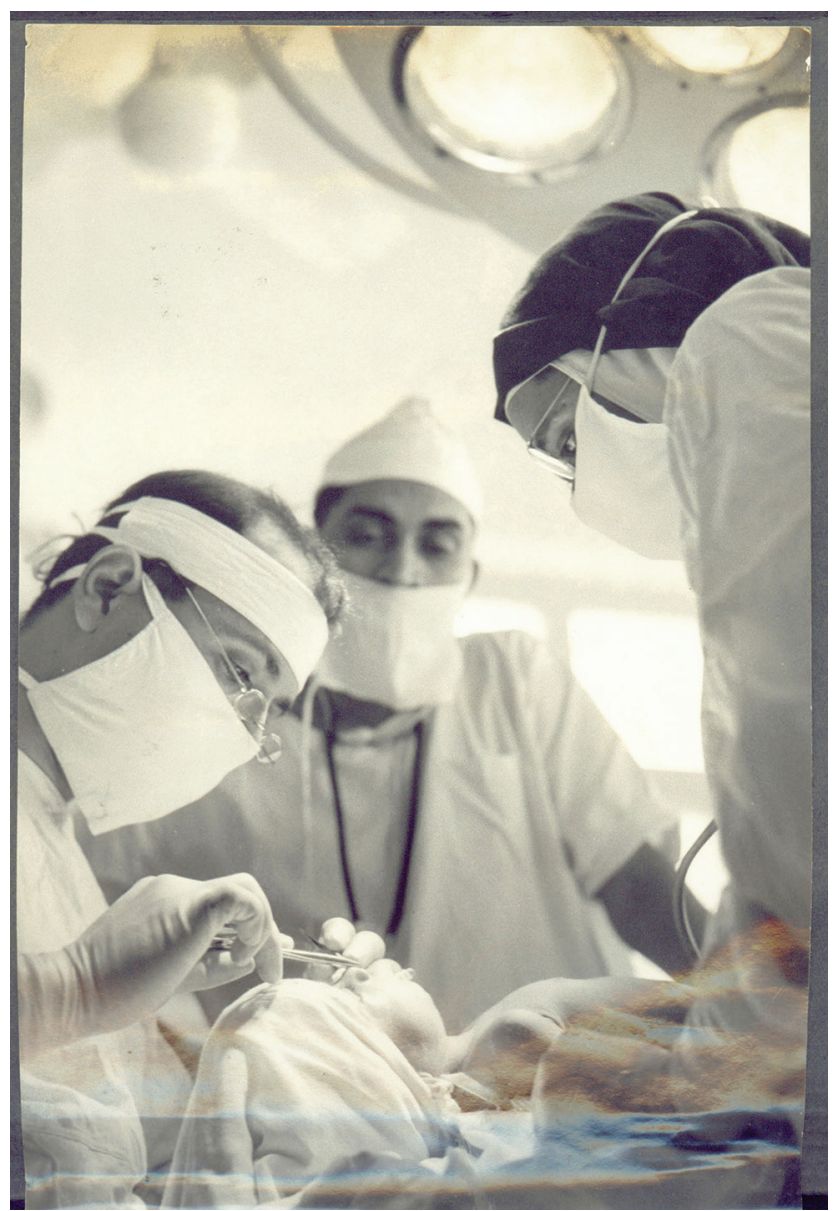

Fig. 3 In his operation theater in the early days. cut ends of the midclavicular fractures, creating a nonunion and enabling early ambulation in these patients.

He gradually set about organizing the hospital, recruited specialists, and trained them to head the various departments. The rock-solid foundation that he laid helped the hospital blossom into the 1500-bedded multispecialty Medical College and Research Institute that it is today.

For the past 40 years or so, he devoted himself solely to the care of cleft lip and palate children. The treatment of such children was his true passion. He was like a wizard weaving his magic on these children with grotesque deformities, dramatically transforming their lives and enabling them to merge unobtrusively into society with a near normal form and function (-Fig. 4).

\section{Contributions to Cleft Surgery}

He made a mark in the repair of the cleft lip and palate very early in his career, and his work found mention in Ralph Millard's magnum opus Cleft Craft in Volumes I and III.,5

For the repair of the unilateral cleft lip, he took a fascination to Millard's rotation advancement procedure and introduced technical refinements, including a protocol to avoid a vermillion notch, ${ }^{6}$ a method of primary cleft lip nose correction in unilateral cleft lips ${ }^{7}$ which included an extensive closed alar cartilage shift, and an aggressive septal repositioning which he and his mentor Charles Pinto started performing almost simultaneously but independent of each other in the 1970s. Those were times when very few cleft surgeons ventured to correct the cleft lip nasal deformity primarily. 


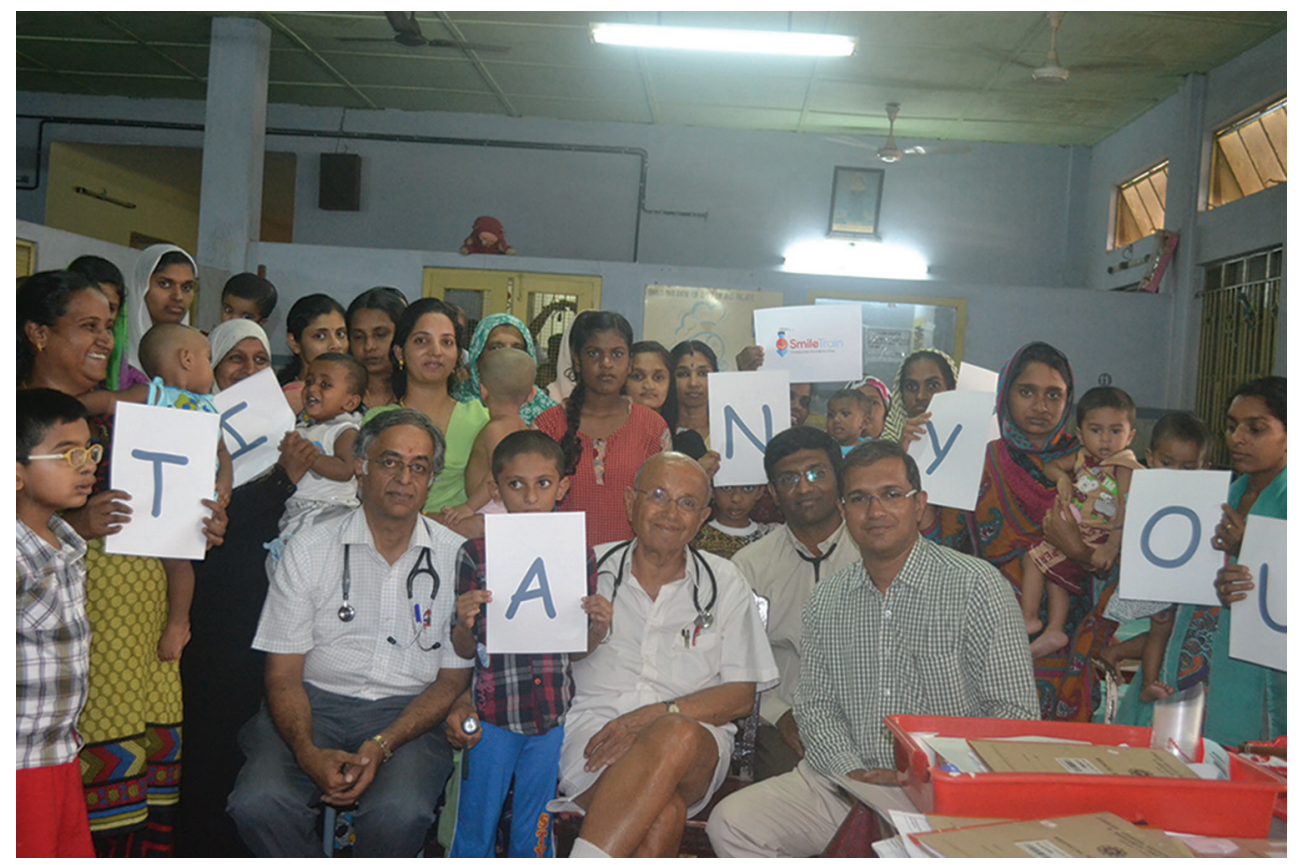

Fig. 4 With his patients.

He pioneered one of the most aggressive forms of septal corrections in primary cleft lip repair. In fact, through numerous publications and presentations at important conferences, he also encouraged other surgeons in the country and abroad to treat the unilateral cleft lip nose deformity during the primary repair. For microform cleft lips, he devised a technique called the Cutaneous Millard's repair with minimal surgical intervention. ${ }^{7}$

He was fascinated with the cleft palate deformity. His meticulous and skillful mobilization of the nasal layers left most visitors to the department dumbfounded. In his hand, the widest of cleft palates, and even ones that had broken down after five to six attempts at repair elsewhere, came together and healed without any disruption. He stressed on the importance of the uvular reconstruction in cleft palates and devised his own original technique to repair $^{8}$ the uvula, producing the most natural-looking uvulas in these children. His debates on the importance of the uvula with prominent global personalities are unforgettable. Many of his cleft palate patients spoke and even sang like their normal noncleft brethren.

I thank God for having placed me here under the guidance of this master to enable me to become a better surgeon and, more importantly, a better human being.

I am enlisting many attributes of his that have helped me in shaping my life and personality and that of scores of others. And I am most certain that there will always be many more attributes that I have missed out. Such is the enormity of the task at hand!

He taught us how important it is to be compassionate by setting an example himself. In the days before Smile Train, when funds were not easy to come by, he would spend much time and effort to determine if the patient could actually pay for the surgery out of his savings or would need to borrow by paying huge interest rates. He would even enquire as to how many mouths the parent had to feed to determine a patient's paying capacity. And then if there was the slightest doubt, he would offer them money from his poor box and perform the surgery free of cost under one of his funds.

He was a man of principles, and with his strong convictions, he would boldly go ahead in his chosen path unmindful of any hurdles. His adherence to principles often brought him into conflict with the concerned authorities. His strong self-conviction was enough to blast all barriers and enable him to achieve the goals that he had set for himself.

He never believed in procrastinating. Though it may sound somewhat against a basic plastic surgery principle of "never doing today what can honorably be put off for the morrow," one could say that he modified this principle to "never do tomorrow what can safely be done today."

He never stopped learning. Even at the peak of his surgical career, he would invite younger surgeons to operate at his center and learn from them. He would then repeatedly watch the recording of their operations and ultimately perform it without a learning curve! He would never embark on any surgical venture without having seen a procedure done by an expert, reading the manuscript describing the surgery, and watching a recorded video of the procedure over and over. Of course, once he had got it right, he would then execute it in his own way. Thus, it came about that at the age of 84 , he started performing an entirely new method of pharyngoplasty that he learned from Philip Chen and then went on to do it on more than 75 patients, getting his best ever results in the correction of velopharyngeal incompetence! 
He was passionate about the history of medicine and believed that one should never forget history. ${ }^{9}$ His trainees and visitors would be enthralled by numerous anecdotes from the history of cleft surgery, and all the great maestros would burst into life before our eyes when this master storyteller told his tales during and in between operative sessions.

He had the greatest respect and reverence for his teachers. He made every effort to propagate their work and would not spare any effort to ensure that his Gurus got the credit that they deserved.

The teaching of his craft was as much his passion as the surgery itself. He would be thrilled when he had attentive trainees and would impart every single fact that he himself had learned to every receptive student. He never discriminated between his trainees with regard to teaching.

He was loyal to his friends, family, and institute and would go to any extent to defend them at all times.

He was a "Kalpaka Vriksha." People of all sorts came to him when in need, and he would not fail to help each accordingly to their need. Many of his old patients would walk into the clinic with vague complaints. He would diagnose the real problem was the need for financial support, and he would do the needful. No one was turned away.

When a friend/colleague approached him with a problem he/she or his/her family was facing, he would instantly absorb the problem as his own and do whatever was needed to overcome the problem. Within minutes, he would call the top experts of the country to obtain a solution.

He always accepted what he did not know. For example, he would always say that the cleft palate speech problem had not been fully understood and had not been solved. He was actually rebuked by some of his trainees for this admission.

Reading was a passion for him. He would read widely on various topics. And with cleft surgery, he would sometimes read the same book over and over again and draw new insights that had been lost to him previously. He would then go on to apply the information thus gained to improve his surgical technique.

He took great care in selecting a good team. Once selected, they became his colleagues, and they were never looked down upon. He would give equal importance to everyone's thoughts. He did not believe that knowledge flowed only one way from the elder to the younger person. He encouraged his junior colleagues to take up newer avenues, and would observe their work closely.

He was one of the greatest orators of our times. However, the success of his speeches was never fortuitous. When he was to make a presentation at a conference or any forum, he followed the same meticulous attitude that he utilized with his surgical technique. He called himself a "neurotic." He would begin preparation of his manuscript as soon as he had decided on the topic then he would complete the write-up overnight. Then, he would begin to read it over and over again and practice the slide presentation with one of us, changing the slides for him at the designated time. We would have a copy of the speech and mark the slide changes just as he would on his copy. Ultimately, when he made his presentation, the slides would be changed with a natural flow without him having to call out for the next slide. And he would know each and every word that he was to utter as he had practiced it several times.

He was very attached to his wife and family. However, the nature of his work culture demanded that he could not spend as much time with them as they would have liked him to. Nonetheless, the entire family, especially his wife, Mrs. Gulnar Adenwalla ( - Fig. 5), were always very understanding and supportive of him and his work, and he never failed to acknowledge this support in every public forum.

Among his passions was cricket (the classical version, not the modern abbreviated ones. He himself was a fine and an

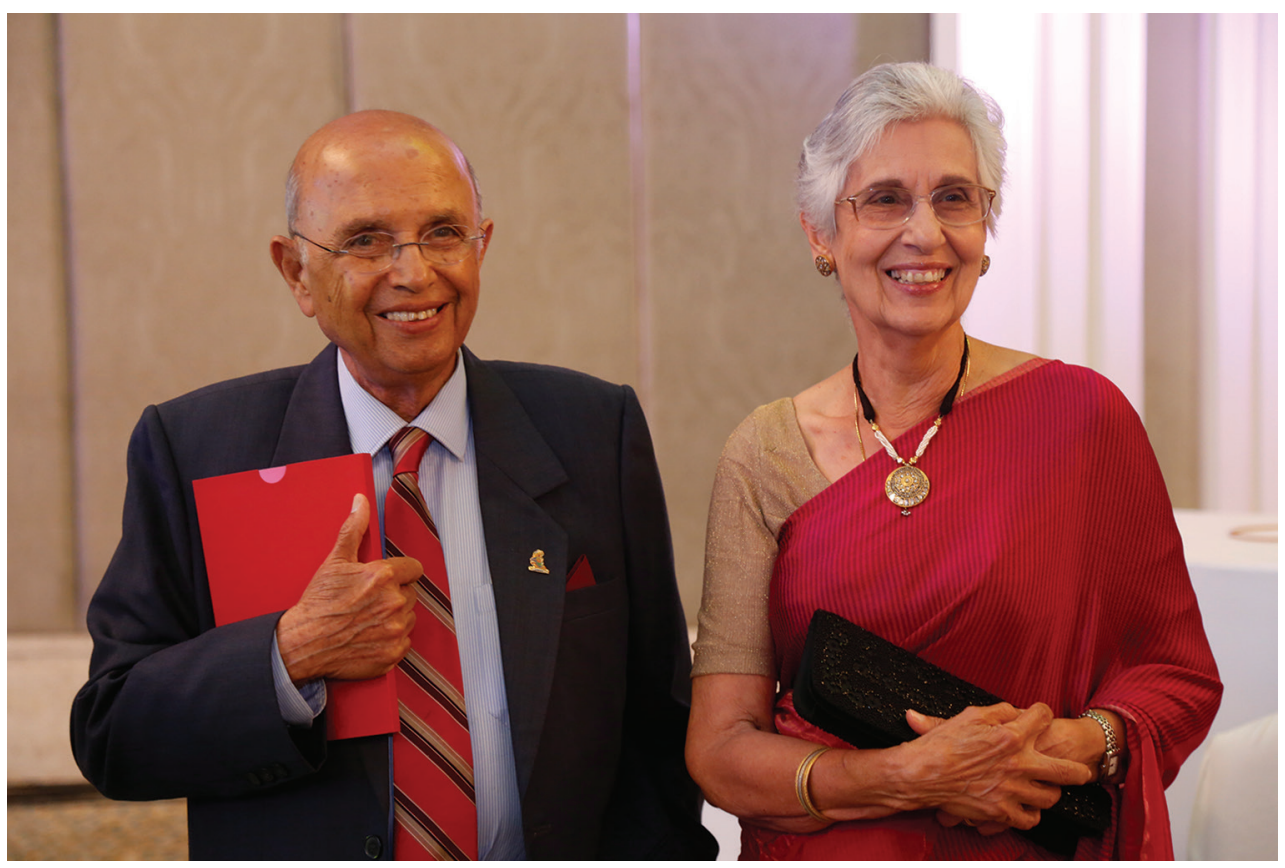

Fig. 5 With his wife Gulnar. 


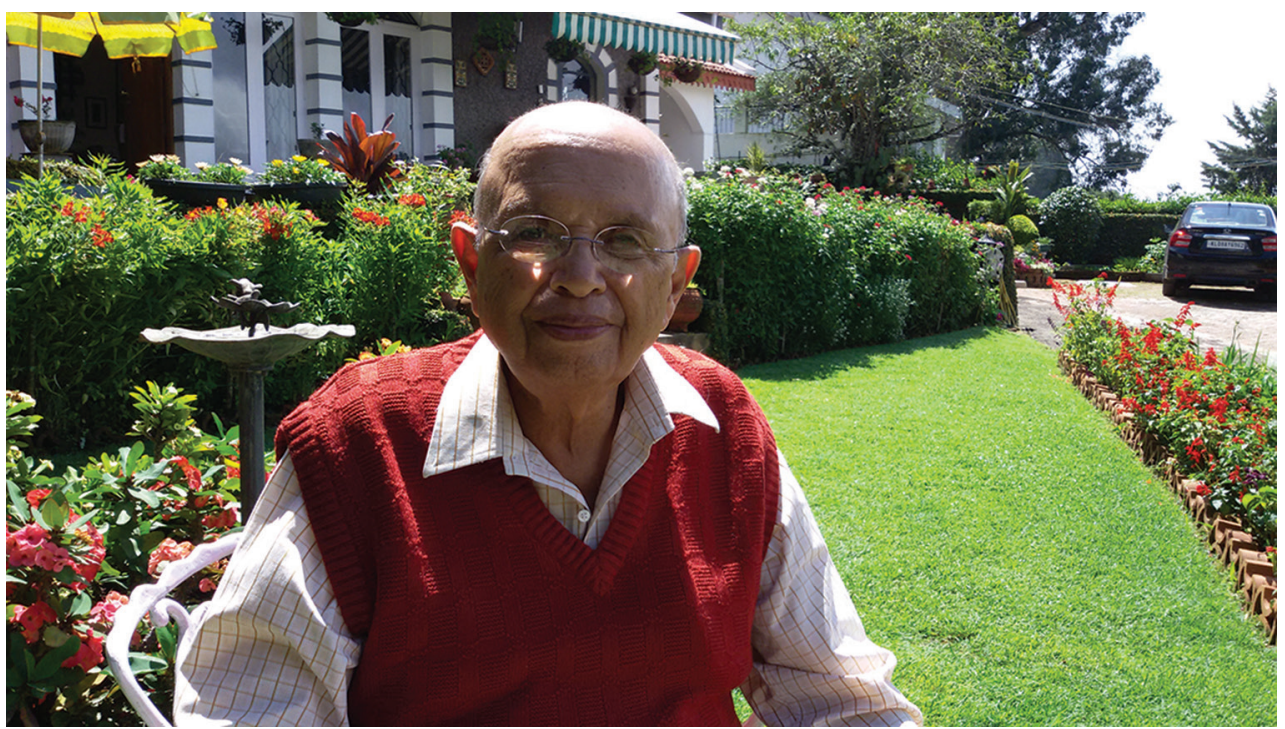

Fig. 6 Relaxing in his garden.

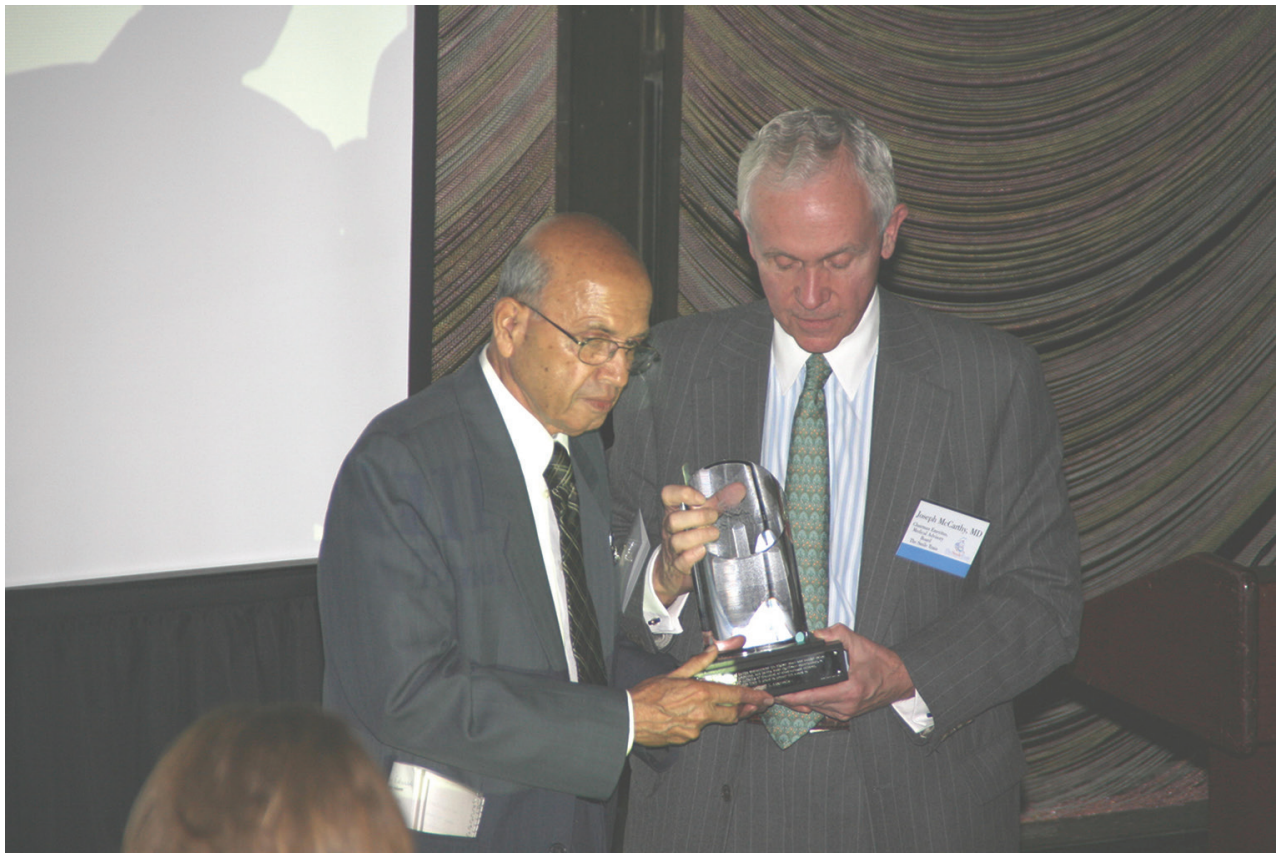

Fig. 7 Receiving the Joseph McCarthy Award.

ardent cricketer in his early days, being an opening batsman and a wicketkeeper for his university team. He was also a golfer (until a few years ago), and another passion of his was poetry (he could recite several long poems till his very end). He had high regard for Winston Churchill and Napoleon and never tired of reading books on them ( - Fig. 6).

He was a Parsi and, like most of his kind, loved good food and wine but never overindulged. Avatar Meher Baba was his spiritual Guru, whom he had met in Ahmednagar and whose Avatar concept was an inclusive philosophy that Dr. Adenwalla truly followed.

He received some great awards like the Joseph McCarthy Award for Excellence in Medicine and Humanitarian services in November 2006 ( - Fig. 7) and the Sushruta Oration in 1999 by the Association of Plastic Surgeons of India. He delivered a guest lecture at the International Cleft Lip and Palate foundation in Zurich, 2000, where he was awarded a citation which reads "in recognition of outstanding contributions in supporting patients with cleft lip and palate and advancing the medical skills in developing countries with deep gratitude and thankfulness." He was chosen as the Plastic Surgeon of the Year by the Association of Plastic Surgeons of India a few years ago. He was offered the Lifetime Achievement award by the Kerala Chapter of the Association of Plastic Surgeons of India (KPSA) in 2018. There were. Of course, many more such awards. 


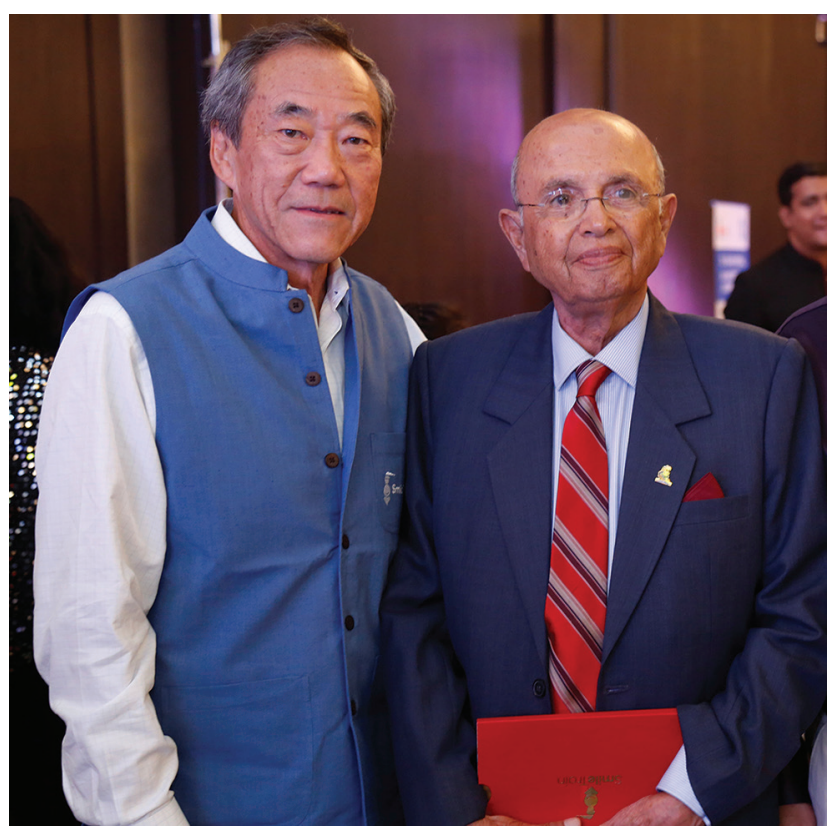

Fig. 8 With Charles Wong at STARS Chennai 2015.

However, the only reward that he truly coveted was the smiles on the faces of his patients and their parents after he had waved his magic wand on them.

He was one of the few great surgeons who never sought any post or position for self-aggrandizement, He was content in toiling along silently in the relative wilderness of Kerala until his friend Suresh Tambewekar dragged him out into the limelight, getting him to share his surgical experiences on clefts at the Cleft Update Conference in Mumbai in 1998. Such was his mettle that coveted posts beseeched him, thus enhancing their own value! He became the first elected president of the Indian Society of Cleft Lip, Palate \& Craniofacial Anomalies by a unanimous decision of the entire association. $\mathrm{He}$ also represented the country on the Medical Advisory Board, Smile Train New York, until the last few years, and he was a Member of the Advisory Committee, Smile Train India, till the very end ( - Fig. 8 ).

Above everything, was his missionary ethos: "Never approach the portals of a hospital with the mind of a money changer," was one of his favorite guiding principles. He never indulged in private practice. Nor did he let any private agency influence his choice of treatment. He wrote at length on medical ethics and also spoke out in various forums exhorting doctors to avoid unethical practices. He led by setting an example, and followed the strictest ethical values throughout his life.

Dr. Adenwalla was a unique medical missionary who left us for his heavenly abode on May 27, 2020, and his loss is an irreplaceable one. However, his legacy is up there as a beacon for all of us to follow. He will continue to live on in the smiles of the more than 20,000 patients whom he worked upon.

\section{Conflicts of Interest}

None declared.

\section{References}

1 Vivekananda S, Lectures by Swami Vivekananda on Raja Yoga Also Pantanjali's Yoga Aphorisms, with Commentaries, and Glossary of Sanskrit Terms In chapter VI Pratyahara and Dharana Routledge Cornell University Library; 2009

2 Adenwalla HS. Icon of this issue - Dr. Charles Pinto. Indian J Plast Surg 2009;42 Suppl(Suppl):S8

3 Patel CV, Adenwalla HS. Treatment of fractured clavicle by immediate partial subperiosteal resection. J Postgrad Med 1972;18(1):32-34

4 Dr MJr, Early proponents of the rotation advancement principle. In: Millard Dr. Jr. ed. Cleft Craft. The Evolution of its surgery 1. The Unilateral Deformity. Boston: Little Brown; 1976 208-209

5 Dr MJr, Refining the V-Y palate repositioning. In: Millard Dr. Jr. ed. Cleft Craft: III. Alveolar and Palatal Deformities. Boston: Little Brown; 1976438

6 Narayanan PV, Adenwalla HS. Notch-free vermillion after unilateral cleft lip repair: The Charles Pinto centre protocol. Indian J Plast Surg 2008;41(2):167-170

7 Adenwalla HS. Narayanan P.V. Primary unilateral cleft lip repair. Indian J Plast Surg 2009;42(Suppl):562-570

8 Adenwalla HS, Narayanan, PV, Primary cleft palate repair. In: Varghese M, ed. Surgical Correction of Facial Deformities. New Delhi: Jaypee Brothers Medical Publishers(P) LTD; 2010 153-164

9 Adenwalla HS. Mayo clinic. Indian J Plast Surg 2015;48(2): 227-230 